\title{
A coerência em narrativas escritas escolares: uma análise piagetiana
}

\section{Coherence in school written narratives: a Piagetian analysis}

\author{
Flávia Isaia Pinheiro ${ }^{1}$ \\ Maria Luiza Rheingantz Becker ${ }^{2}$
}

\begin{abstract}
RESUMO
Este artigo aborda o tema da produção textual escolar e reúne contribuições de estudos das áreas da Linguística, Educação e Psicologia, realizados para tese de doutorado (PINHEIRO, 2012). Tem como propósito estabelecer articulações teóricas entre os processos gerais de desenvolvimento cognitivo e a construção da coerência em narrativa-conto como conhecimento específico da linguagem escrita. Os estudos que correspondem ao quarto período da obra de Jean Piaget $(1977,1978,1997)$ mostraram-se fundamentais para a análise das evidências, por abordarem conceitos explicativos do progresso cognitivo através dos processos da tomada de consciência e da lógica das significações. A pesquisa de campo foi realizada com estudos de casos múltiplos em uma escola da rede municipal de ensino de Porto Alegre. O artigo apresenta as diferenças encontradas na escrita das narrativas pelas estudantes e extrai delas as evidências importantes tanto para subsidiar práticas escolares como para ampliar o campo de pesquisas que envolvem as narrativas escritas.
\end{abstract}

Palavras-chave: narrativas escritas escolares; operatividade; coerência; implicação significante.

\footnotetext{
ABSTRACT

This paper addresses school texts and assembles contributions from the fields of Linguistics, Education and Psychology for the doctoral thesis

DOI: $10.1590 / 0104-4060.35501$

1 Universidade Federal do Rio Grande do Sul. Porto Alegre, Rio Grande do Sul, Brasil. Av. Santos Dias da Silva, S/N. CEP: 91550-500.

2 Universidade Federal do Rio Grande do Sul. Porto Alegre, Rio Grande do Sul, Brasil. Av. Paulo Gama S/N, Prédio 12201. CEP: 90046-900.
} 
(PINHEIRO, 2012). It aims to make theoretical articulations between general processes for cognitive development and the construction of coherence in tale narratives as a specific expertise in written language. Studies on the fourth stage of Piaget's work $(1977,1978,1997)$ were fundamental for the analysis of evidences as they provided concepts which explained the cognitive development through the processes of grasp of consciousness and logic of meanings. The field research was conducted through multiple case studies in a public municipal school in Porto Alegre. This paper presents the differences found in the students' narratives writing and the important evidences for both supporting school practices and widening the research on school written narratives.

Keywords: school written narratives; operativity; coherence; significant implication.

\section{Introdução}

Este artigo tem como objetivo apresentar elementos de nossa tese de doutorado (PINHEIRO, 2012) que dizem respeito tanto aos processos gerais de desenvolvimento cognitivo (tomadas de consciência e implicações significantes) como à construção da coerência em narativas-conto como conhecimento específico da linguagem escrita (coerência e coesão textuais nas atividades epilinguísticas em versões de uma mesma história). A relevância da pesquisa relaciona-se com a necessidade de conhecermos como os alunos constroem a narrativa escrita. Os elementos aqui apresentados fornecem informações nesse sentido e convidam o leitor a pensar, de forma fundamentada, em propostas de trabalho que possibilitem regulações ativas do aluno no seu processo em busca de coerência nas narrativas escritas. Para iniciar, destacaremos algumas ideias de Geraldi (1997) que introduzem o artigo.

Ao fundamentar-se numa perspectiva dos estudos linguísticos sobre textos e discursos, o autor afirma que "o específico da aula de português é o trabalho com textos" (GERALDI, 1997, p. 105). Segundo ele, para produzir um texto é preciso que o sujeito diga algo a alguém, escolha estratégias para o que tem a dizer e tenha uma razão para fazê-lo ao constituir-se como locutor. A coerência é uma das características mencionadas por Geraldi em seu conceito de texto: "Um texto é uma sequência verbal escrita coerente formando um todo acabado, definitivo e publicado" (GERALDI, 1997, p. 101, grifo nosso).

Convém destacar que nos textos narrativos são utilizados recursos de ordenação temporal que não aparecem em textos descritivos (KOCH; TRAVAGLIA, 
1990). Esse aspecto chama a atenção para o estudo do desenvolvimento da noção de tempo na criança (PIAGET, 1980): a noção de tempo supõe a de espaço, sendo o tempo solidário da causalidade. Ele está para as operações explicativas como a ordem lógica está para as operações implicativas.

Considerando que "[...] é para o outro que se produz o texto" (GERALDI, 1997, p. 102), ocorrerá a necessidade de explicar para o leitor, tanto através da voz do narrador como da voz dos personagens, as situações que acontecem no decorrer da história. Ao fazer isso, o sujeito estabelece uma sequência de acontecimentos através da ordenação (antes/depois) entre os fatos da história. A utilização de conectivo ou verbo indicando o vínculo causal sinaliza para a capacidade que o sujeito tem de estabelecer relações causais entre os fatos.

Existe um tempo operatório que consiste em relações de sucessão e de duração que não se limitam à percepção imediata, externa e interna. Essa solução coerente encontrada na ordem das sucessões supõe a reversibilidade do pensamento (PIAGET, 1980).

\section{A busca pela coerência nas narrativas escritas}

Com relação aos tipos de textos narrativos abordados por Dalla Zen (2006), descobrimos que uma narrativa-conto pressupõe uma estrutura de construção textual bem mais complexa que uma narrativa-relato, pois envolve a criação de um nó narrativo ou de um acontecimento problemático que depende da capacidade de operar sobre simples possibilidades tratadas como hipóteses. O esforço que é feito pelo sujeito no sentido de englobar relações aparentemente reais no conjunto daquelas concebidas por ele como possíveis nada mais é do que a busca pelo estabelecimento da coerência entre essas ligações. Segundo Piaget e Inhelder (1976, p. 193-194): "É possível tudo que não é contraditório. Mas o não contraditório é, rigorosamente falando, o conjunto das transformações reversíveis $[\ldots . .$.$] ".$

Podemos dizer, então, que quando o enredo de uma narrativa-conto apresenta elementos contraditórios, estamos diante de uma irreversibilidade operatória, traduzida sob a forma de incoerências locais, cujo acúmulo pode tornar o todo do texto incoerente. Nesse caso, Koch (1989) explica que o mau uso dos elementos linguísticos de coesão provoca incoerências locais pela violação de sua especificidade de uso e função, dificultando a compreensão do texto e a construção da coerência pelo leitor/ ouvinte. Isso significa que a coesão tem relação com a coerência na medida em que é um dos fatores que 
permite calculá-la ${ }^{3}$. Entretanto, esta não se dá apenas na sequência linguística, pois depende dos usuários e da situação.

O que está em jogo é a manipulação de elementos linguísticos por operações argumentativas (ligadas à intencionalidade) e processos cognitivos realizados entre os usuários do texto. Desta forma, ao procurar a solução de um problema de incoerência na narrativa-conto, um erro corrigido do sujeito escrevente pode ser mais fecundo que um êxito imediato, porque, de acordo com Piaget (1987), a comparação da hipótese falsa e suas consequências proporciona novos conhecimentos, e a comparação entre erros dá lugar a novas ideias.

Todos esses aspectos devem ser considerados na habilidade de produzir narrativas escritas coerentes, uma vez que pesquisas nacionais sobre narrativas infantis (LINS E SILVA; SPINILLO, 2000) indicam que após a alfabetização existe uma progressão, um caminho a ser percorrido para a aquisição de um esquema narrativo mais elaborado que se manifesta na escrita de textos.

Se os anos escolares após a alfabetização contribuem para o desenvolvimento da escrita de histórias é porque o adulto, estando mais avançado do que a criança, pode ajudá-la nessa evolução ao longo do processo educativo familiar ou escolar (PIAGET, 1991). É exatamente aí que a situação de produção e a natureza do tipo de apoio fornecido ocupam um lugar importante, quando consideradas as capacidades e incapacidades do sujeito de raciocinar sobre os "possíveis narrativos". Cada "possível" alcançado pelo sujeito constitui uma construção e uma abertura (novidade positiva), mas também uma nova lacuna a preencher (PIAGET, 1985).

Quando uma habilidade narrativa prescinde de apoios externos, conforme exemplificado por Lins e Silva e Spinillo (2000), é porque o sujeito já consegue raciocinar sobre possíveis narrativos, incluindo o necessário. Isso significa que, ao englobar relações no conjunto daquelas concebidas por ele como possíveis, o sujeito consegue estabelecer uma coerência entre essas ligações. Encontra-se, nas palavras de Piaget (1985), na posse do sistema cognitivo que ele denomina de sistema presentativo fechado, de esquemas e estruturas estáveis.

Podemos interpretar que, nesse processo de produzir histórias coerentes, o necessário encontra-se justamente no desfecho elaborado pelo sujeito, tendo em vista que uma história coerente deve ser finalizada com uma conclusão ou desfecho que está em relação estreita com os episódios narrados (SPINILLO; MARTINS, 1997). Não é por nada que a principal dificuldade das crianças da pesquisa das autoras na produção de uma história coerente tenha sido a de elaborar um desfecho, uma vez que o necessário exprime o processo de autor-

3 Segundo a autora, as duas grandes modalidades de coesão, a coesão remissiva ou referencial e a coesão sequencial, ajudam a estabelecer a coerência na interpretação dos textos. 
regulação e fechamento de suas composições e só pode ser alcançado quando o problema é resolvido, problema este entendido aqui como sendo a relação estreita a ser estabelecida entre o desfecho e os episódios narrados, no sentido de coordenar e integrar as diversas partes da história.

Concordamos com Spinillo (2001) que a escrita de narrativas envolve uma atividade cognitiva complexa, e acrescentamos que o conceito de implicação significante de Piaget e Garcia (1997) permite uma melhor compreensão a esse respeito, conforme abordaremos a seguir.

\section{O conceito de implicação significante}

A implicação significante é uma forma de inferência que constitui a operação central da lógica das significações que Piaget se propunha a elaborar com R. Garcia, em seu último trabalho. Trata-se de uma ligação que parece necessária, do ponto de vista do sujeito, entre dois enunciados, operações ou ações que têm uma significação em comum (PIAGET; GARCIA, 1997).

Os graus de implicações significantes aparecem em três níveis diferentes, conforme os autores: I) Implicações "locais", que permanecem restritas a dados limitados e a contextos muito particulares; II) Implicações "sistêmicas", quando já se inserem em um sistema de relações, embora sejam compreendidas somente por passos sucessivos entre elementos próximos; III) Implicações "estruturais", referentes às composições internas de estruturas já construídas. Neste nível existe a compreensão endógena da "razão" dos fatos gerais e observados. As relações gerais do Nível II se tornam necessárias.

Retornaremos a esses três níveis mais adiante, na apresentação de nossos resultados de pesquisa. Pensemos agora que se $A$ (situação inicial da história) implica $B$ (situação-problema), a forma proativa ou condicionante consiste em considerar $B$ (situação-problema) como uma consequência derivada de $A$ (situação inicial da história); a forma retroativa, em considerar que $B$ (situação-problema) implica $A$ (situação inicial da história) a título de condição prévia; e a forma justificadora, em ligar condições e consequências pelas conexões necessárias que exprimem as razões. A isso, acrescenta-se $C$ (situação final da história), que implica $A$ e $B$.

A passagem da ação para a conceituação consiste em uma espécie de tradução da causalidade em termos de implicação, que se manifesta justamente no esforço de estabelecer relações entre as diversas partes da história, ordenando-as, coordenando-as e integrando-as. Para que isso possa ocorrer, a determinação 
das razões dos acontecimentos da história, em especial da situação-problema, passa a ser um elemento fundamental fornecido pelo sistema das implicações significantes, uma vez que o mundo das "razões" se amplia sobre os possíveis.

Trata-se, portanto, de coordenar a situação-problema num sistema de conjunto, no qual o desenvolvimento da história vem a ser o desenrolar da ação, que se confunde, então, com o próprio processo de transformação da situação inicial em situação final.

Entretanto, não se trata de uma tarefa fácil. Aprendemos com Piaget (1977) que a tomada de consciência, ou seja, os graus de compreensão do sujeito dependem de regulações ativas que envolvem escolhas mais ou menos intencionais. Essas regulações ativas dizem respeito ao resultado do esforço das coordenações mentais das alunas no sentido de reorganizarem conceitualmente seu conhecimento letrado inicial de histórias. Trata-se, portanto, de um alargamento do campo da consciência, no duplo sentido antecipador (encontrar os meios para tornar coerente a estrutura narrativa) e retrospectivo (reconstituir a sequência narrativa já escrita). Neste caso, aspectos como as atividades epilinguísticas (GERALDI, 1997) e as versões da escrita de uma história (CALIL, 2008) ganham destaque enquanto formas de regulações ativas.

De acordo com Piaget (1997), ao agir a criança costuma preocupar-se com seus pontos de chegada, negligenciando os de partida. É como se uma chegada ao objetivo não supusesse um afastamento relativo a uma situação de partida ou uma modificação desta. A esse respeito, caberia observarmos o quanto os alunos da educação básica valorizam ou não a situação inicial da história como sendo o ponto de partida a ser transformado. Essa valorização requer uma ação operativa que tende a tornar-se operação, e uma operação é sempre solidária de seu contrário, portanto de um sistema de conjunto que comporta múltiplas coordenações (PIAGET, 1978). No caso das narrativas escritas, o que está em jogo no processo de transformação da situação inicial em situação final é a coordenação das três categorias obrigatórias para a constituição de um esquema canônico: 1) situação inicial; 2) processo de complicação; 3) resolução ou fim do processo (AXT, 1996).

Para que esta coordenação ocorra, as propostas de narrativa escrita que exigem a intervenção de abstrações "reflexivas" (PIAGET, 1977) a partir das ações ou operações dos alunos tornam-se fundamentais. Uma proposta em que os alunos tenham que escolher os meios que possibilitam a articulação entre início-fim, por exemplo, é supostamente uma tarefa mais difícil de ser bem-sucedida quando comparada com uma história livre, justamente por envolver a coordenação dos "possíveis narrativos" a serem inventados pelo sujeito, ou seja, por envolver uma maior regulação ativa. 
Tendo em vista tanto a lógica das significações como os resultados de pesquisas sobre narrativas infantis (SPINILLO, 1996; SPINILLO; MARTINS, 1997), veremos a seguir que a diferença na qualidade das narrativas escritas está relacionada com os tipos de regulações apontados por Piaget (1978) no que se refere aos progressos da ação.

\section{Metodologia de investigação}

O objetivo geral de nossa investigação foi compreender como as operações mentais do sujeito se expressam nas atividades que envolvem a escrita da narrativa-conto na escola. Tendo em vista que a questão central levantada tinha caráter explanatório (Como o aspecto operativo do pensamento do sujeito possibilita a coerência, especialmente na escrita da narrativa-conto?), decidimos utilizar o estudo de caso em nossa proposta investigativa.

Utilizamos, então, o estudo de casos múltiplos (YIN, 2010) como delineamento de pesquisa e as contribuições do método clínico em conversações durante a observação sistemática dos sujeitos envolvidos. Nosso objetivo foi mostrar o poder explicativo da Epistemologia Genética de Jean Piaget para realizar uma análise do processo de construção de conhecimento durante as aprendizagens da escrita de narrativa-conto na escola e não realizar uma análise quantitativa.

A coleta das evidências foi realizada em 19 encontros extraclasse com alunas da turma em que a pesquisadora atuava como professora. As alunas frequentavam o $5^{\circ}$ ano de escolaridade em uma escola pública da Rede Municipal de Ensino, em Porto Alegre, e possuíam idades entre 10 e 12 anos.

Nas situações de produção constituídas para a coleta das evidências foram introduzidas tarefas individuais, em duplas e em grupo. Todas as tarefas foram elaboradas com o intuito de mobilizar a razão dos acontecimentos da história, o "como" da situação-problema a ser inventado (causalidade), ou seja, com o intuito de envolver a reflexão no sentido de uma reorganização conceitual de forma a coordenar a situação-problema num sistema de conjunto.

Durante o questionamento feito às participantes da pesquisa, consideramos como fundamentais dois tipos de repostas para análise das evidências: a resposta desencadeada e a resposta espontânea, inspiradas no método clínico piagetiano À semelhança de Delval (2002), também utilizamos dois tipos de perguntas: as perguntas básicas, que fizeram parte do roteiro de planejamento da tarefa proposta, e as perguntas complementares, tanto em função das diferentes nar- 
rativas escritas como em função do próprio esforço da pesquisadora no sentido de aproximar-se da lógica das alunas.

Os dados coletados foram analisados em três grandes categorias de análise: 1) Implicação significante (situação-problema e desfecho); 2) Estruturação do Real (níveis de coerência e recursos coesivos); 3) Descentração/Tomada de Consciência: regulações e construção de novos possíveis. As duas primeiras categorias relacionam-se com a análise da narrativa escrita (produto final) e a terceira categoria refere-se fundamentalmente às situações dialogadas que ocorreram durante a realização das tarefas propostas.

A investigação da unidade de análise, a operatividade do pensamento de pré-adolescentes durante a construção da coerência em textos de narrativa-conto, foi realizada com quatro alunas, escolhidas dentre as sete, que aceitaram participar da pesquisa. Foram considerados os seguintes critérios de escolha: a presença de diferentes patamares de conhecimento expressos durante as situações de produção e o maior número de regulações ativas apresentadas durante o trabalho, fundamentais para o conhecimento do progresso qualitativo do desenvolvimento da coerência nas narrativas escritas do ponto de vista da Epistemologia Genética.

Cada caso foi constituído pelo registro da produção escrita e pelos dados de observação das condutas das alunas e de seus diálogos com as colegas e a pesquisadora, durante os encontros ao longo dos seis meses de desenvolvimento da intervenção. Os casos foram organizados e analisados um a um em sua evolução longitudinal para depois serem relacionados entre si para caracterizar as diferenças no desenvolvimento qualitativo da coerência encontradas na escrita das narrativas das alunas. A seguir, apresentaremos os resultados de nossa investigação que dizem respeito a essas relações entre os casos. Esta opção e o uso de nomes fictícios buscaram preservar a identificação das alunas participantes.

\section{Análise dos resultados}

Serão apresentados os resultados dos quatro casos, em conjunto. Foi constatado que as primeiras mudanças evidenciadas, especialmente nas tomadas de consciência de Amélia (11a 4m), Carolina (11a 4m) e Stela (11a 8m), estiveram relacionadas com as coordenações de suas ações no que se refere à apresentação dos personagens para o leitor, através de apagamentos, substituições e acréscimos que envolveram regulações ativas que se referem ao uso da coesão referencial. Junto a esse esforço, alia-se outro, que consiste em conseguir ordenar e coor- 
denar os eventos relacionados com o início e o meio da história. Para fazerem isso, as meninas passam a utilizar nexos que expressam a coesão sequencial. Entretanto, o uso adequado desses nexos não é logo alcançado, pois envolve diferentes graus de compreensão dos sujeitos no que se refere às ligações de tempo, espaço e causalidade.

Chama a atenção que o uso desses nexos é acompanhado por regulações ativas que passam a considerar o leitor no que se refere à convenção que regula o sistema formal de apresentação textual. Assim, nota-se que as autoras passam a distinguir melhor a fala do narrador da fala do personagem ao mudarem de linha em seus parágrafos e ao fazerem uso do sinal de dois pontos e do travessão. Vale lembrar que esse aspecto está relacionado tanto com a compreensão de conceitos ligados ao tempo (ordenação), no que se refere ao fato de anunciarem antes o personagem que irá falar depois, como com o processo que conduz do egocentrismo à descentração, já que escrevem para serem compreendidas pelo leitor.

Essa preocupação com o sujeito-leitor, que se manifesta tanto no uso da convenção como nos momentos em que as alunas passam a identificar e/ou solucionar contradições existentes ao longo da narrativa, passa a existir quando já conseguem antecipar possibilidades. Dito de outra forma: a preocupação com o sujeito-leitor passa a existir quando já conseguem elaborar relações lógicas que se apoiam sobre implicações significantes do Nível II, chamadas de implicações sistêmicas (PIAGET; GARCIA, 1997). Nesse nível começam os juízos sobre o que é possível e o que não é. É daí que decorrem as correções, expressas através de rasuras escritas e orais (CALIL, 2008) tanto no próprio texto como em revisões de textos de colegas, cuja função (e intenção!) é suprimir, substituir, adicionar e deslocar elementos ditos ou escritos, até chegar a uma versão final de narrativa escrita.

São, portanto, as regulações ativas que levam o sujeito a considerar vários fatores ao mesmo tempo ao longo da narrativa (coesivos, coerência e estrutura textual), e todas as suas tentativas visam ao ajuste dos meios, tanto no sentido antecipador (encontrar progressivamente os meios para tornar coerente a estrutura narrativa) como retrospectivo (reconstituir a sequência narrativa já escrita).

No entanto, será somente com as implicações significantes do Nível III, chamadas de implicações estruturais (PIAGET; GARCIA, 1997), que ocorrerá o uso adequado da convenção que regula o sistema formal de apresentação textual. Isso se dá porque as relações do Nível II tornam-se necessárias, dando lugar a uma nova forma justificante de implicação, que vincula as formas proativas e retroativas por conexões necessárias relacionadas com as "razões" dos acontecimentos da história.

Assim, se nas implicações sistêmicas anteriores o desfecho da história não apresentava uma relação clara com o evento principal, é justamente com as im- 
plicações estruturais (PIAGET; GARCIA, 1997) que ocorre a elaboração de um desfecho em estreita conexão com os eventos narrados no desenvolvimento da história. Isso ocorre porque existe, da parte do sujeito, a compreensão endógena das "razões" dos acontecimentos da história, em especial da situação-problema, que agora é coordenada mentalmente por ele num sistema de conjunto.

É assim, por exemplo, que, ao analisar uma história de Carolina em determinada situação de produção, Raquel afirma que: "Ela tinha que botar mais coisas. Na parte do menino ela podia botar mais, mais assim, suspense", manifestando compreensão acerca do ponto exato do texto em que deveria existir a situação-problema. Quanto ao desfecho, sugere que a colega escreva “Agora está tudo bem" e "explique o que aconteceu". Essa sugestão indica que Raquel, diferente de Carolina nesse aspecto, identifica a contradição existente no final do texto e estabelece uma relação de implicação entre o desfecho e os acontecimentos narrados anteriormente na história. Depois, Raquel parece não se satisfazer mais com sugestões de melhorias locais (situação-problema e desfecho), pois diz para a colega "incrementar mais, fazer toda a história de novo". Pode-se inferir que Raquel passa a considerar necessária uma transformação que conduza a narrativa de um estado inicial (situação inicial da história) a um estado final (situação final da história) que comporta múltiplas coordenações e a lógica das significações.

A esse respeito, verificou-se em uma das situações de produção que o esforço das coordenações mentais de todas as meninas recaía sobretudo na introdução, no sentido de estabelecerem relações de implicação entre os fatos que se sucediam entre a introdução e a sequência da história. Convém destacar novamente que, ao relacionar os eventos que preenchem o tempo na história, o sujeito estabelece uma sequência de acontecimentos através da ordenação (antes/ depois) entre os fatos que acontecem ao longo da narrativa. Trata-se, de acordo com Piaget (1980), da ordem das sucessões. Nesse sentido, as implicações estruturais evidenciadas nas narrativas escritas de Raquel, Amélia e Stela em uma mesma situação de produção chamam a atenção para um tempo operatório que consiste em relações de sucessão e duração, fundadas em operações análogas às operações lógicas.

Desta forma, o conceito de tempo torna-se um elemento fundamental nesse caminho que busca a coerência na narrativa-conto. As ligações temporais, causais e lógicas estabelecidas pelas meninas parecem indicar, deste modo, a sua chegada à representação conceitual de ordem operatória, na medida em que expressam linguisticamente na referida narrativa escrita os seguintes usos adequados de elementos coesivos: "nem notaram que", implicando simultaneidade de tempo, e "bem forte que", indicando causa e efeito (Stela); "então" (Raquel); "mas 
como?" e "Ah" utilizado com o sentido de "então", além do uso do tempo verbal adequado e da descrição do tempo-relógio várias vezes na narrativa (Amélia).

É importante considerar que a chegada a esse tempo operatório envolve o grau de reversibilidade atingido pelo raciocínio porque a ordem da sucessão, como a seriação dos acontecimentos uns em relação aos outros na história, supõe necessariamente um jogo de operações suscetíveis de percorrer esses acontecimentos em pensamento. Assim, ordenar acontecimentos é segui-los tanto na ordem $A$ antes de $B$ e $B$ antes de $C$ como na ordem $C$ depois de $B$ e $B$ depois de $A$, conforme demonstramos anteriormente ao explicar a implicação significante.

Se quisermos saber, por exemplo, se um acontecimento $\mathrm{x}$ na história ocorreu antes do acontecimento y ou o contrário, é preciso remontar dos efeitos às causas, ou partir das causas para os efeitos, de acordo com todos os possíveis narrativos, até que seja encontrado um desfecho coerente com o conjunto das séries ou partes construídas.

É nesse sentido, explica Piaget (1980), que a ordem das sucessões supõe a reversibilidade do pensamento, pois o sujeito passa a introduzir no tempo psicológico uma sucessão racional, por reconstrução operatória e não mais unicamente por reconstituição intuitiva. Mas isso só pôde ser alcançado com as implicações estruturais do Nível III, porque no Nível I, das implicações locais, Carolina apenas reunia os personagens de maneira confusa no início da narrativa, não conseguindo conservá-los no que se referia a suas posições e ações ao longo da história. Quando os personagens surgiam, não existia uma explicação em relação ao lugar em que estavam (espaço) e a "quando" os fatos ocorreram (tempo). Ou então os fatos narrados aconteciam num intervalo de tempo próximo uns dos outros, com "saltos" que dificultavam a compreensão das ligações causais e lógicas entre as partes da história, especialmente do meio para o final da narrativa. Além disso, o uso dos nexos "porque", "quando" e "que" não expressavam relação lógica em nenhuma parte da história. Em nossa tese demarcamos esse Nível de IA, como uma subclasse dentro do Nível I da classificação de Piaget.

Quando, na narrativa de uma determinada situação de produção, Carolina consegue apresentar, nas partes iniciais do texto, uma nítida diferença nas ligações de espaço, tempo e causalidade, manifestando maior facilidade na coesão referencial e esforço na tentativa de estabelecer relações de implicação entre elementos próximos que ligariam a introdução com o meio da história, ela ordena e apresenta um início de coordenação entre essas partes da história. Demarcamos o resultado desse seu esforço de Nível IB em nossa tese porque ainda faltaria integrar essas partes iniciais ao restante da história e criar uma situação-problema, ou seja, antecipar possibilidades. 
Com relação à demarcação do Nível II, das implicações sistêmicas, foi observado em uma das situações de produção que, mesmo Raquel estando atenta aos nexos temporais, apresentando sugestões para o texto da colega e esforçando-se na melhoria de aspectos relacionados ao tempo, espaço e causalidade, permanece em sua narrativa a falta de relação de implicação entre o meio e o final da história. Ou seja, apesar de refletir sobre as partes da história ao conseguir coordená-las nos acréscimos que faz quanto à coesão sequencial e referencial, trata-se de uma coordenação parcial entre as partes da história, pois até o final da tarefa a incoerência em relação ao desfecho permanece inconsciente para Raquel. Para que mantivessem a coerência interna no desfecho, Raquel e a colega teriam que ter invertido a ordem da última frase do texto apresentado a seguir:

Ela nunca mais perdeu sua casa.

E ela ficou muito feliz com isso.

Depois de alguns anos ela comprou uma casa com 7 quartos, cozinha, 2 banheiros, sala de jantar e com pátio.

Isso evidencia que suas inferências não foram suficientes para que alcançassem relações necessárias, já que o desfecho (necessário) não foi alcançado. Observa-se, então, que ainda existe uma confusão no que se refere à sucessão racional do tempo psicológico, conforme mencionado anteriormente. Essa confusão passa a ser solucionada somente no Nível III, das implicações estruturais, quando existe compreensão endógena da "razão" dos acontecimentos que se relacionam com a trama (situação-problema) da história.

Para finalizar esse ponto, reiteramos que as situações de produção que envolvem a mobilização da razão dos acontecimentos da história, o "como" da situação-problema a ser inventado, possibilitam mais regulações ativas dos sujeitos nesse processo em busca de coerência nas narrativas escritas. Essa é uma evidência importante para subsidiar práticas escolares e ampliar o campo de pesquisas que envolvem as narrativas escritas.

\section{Conclusões}

O processo de construção das versões possíveis de uma narrativa-conto envolve o ato inferencial do sujeito escrevente em busca de aperfeiçoamentos 
em sua narrativa. Na evolução das versões possíveis que a narrativa-conto pode apresentar, é possível acompanhar diferentes estados de operatividade dos sujeitos, conforme os graus de implicações significantes propostos por Piaget e Garcia (1997).

Nesse sentido, hoje temos a convicção de que escrever uma narrativa-conto constitui um problema lógico a resolver, porque para solucioná-lo o sujeito necessita estabelecer relações entre significações caracterizadas por implicações estruturais (PIAGET; GARCIA, 1997). É justamente nesse grau de implicação significante que o sujeito consegue elaborar um desfecho em estreita conexão com os eventos narrados no desenvolvimento da história.

Concordamos com Spinillo (2001) que o grande passo no desenvolvimento cognitivo é integrar os diferentes tipos de conhecimento (coesão, coerência e estrutura textual), coordenando esses aspectos em um todo significativo. Porém, acrescentamos que esse passo é possível graças aos processos das tomadas de consciência e da lógica das significações, e que a diferença na qualidade das narrativas escritas está relacionada com as regulações ativas apontadas por Piaget (1978) no que se refere aos progressos da ação.

Os resultados alcançados mostram que as relações entre processos gerais de desenvolvimento cognitivo, como as tomadas de consciência e as implicações significantes, e a construção da coerência em textos escritos em narrativas-conto como conhecimento específico se evidenciam no uso dos elementos de coesão que expressam relações lógicas na articulação do desfecho com a introdução e meio da história e no uso de nexos com valor temporal, bem como na distinção da fala do narrador da fala do personagem através da mudança de linha nos parágrafos e no uso do sinal de dois pontos e travessão.

Podemos pensar, portanto, nas implicações educacionais dos três níveis destacados neste artigo para o processo de ensino-aprendizagem, na medida em que eles fornecem subsídios para os professores compreenderem de que forma se expressam as diferenças qualitativas nas narrativas escritas de seus alunos e pensarem propostas de trabalho que envolvam a mobilização da razão dos acontecimentos da história, do "como" da situação-problema a ser inventado.

Neste artigo, esperamos ter conseguido anunciar um outro passo na literatura sobre o tema da revisão textual (versões possíveis), ainda merecedor de novos estudos, o qual envolve a abordagem de questões específicas sobre a natureza da tarefa e a natureza das respostas do sujeito, aspectos estes indissociáveis do ponto de vista da Epistemologia Genética e com implicações educacionais que interessam à formação de professores. 


\section{REFERÊNCIAS}

AXT, Margarete. Estruturação de histórias no computador e desenvolvimento cognitivo. In: OLIVEIRA, Vera Barros (Org.). Informática em Psicopedagogia. São Paulo: Editora SENAC, 1996. p. 35-53.

CALIL, Eduardo. Escutar o invisivel: escritura e poesia na sala de aula. São Paulo: Editora UNESP; Rio de Janeiro: FUNARTE, 2008.

DALLA ZEN, Maria Isabel Habckost. Foi num dia ensolarado que tudo aconteceu: práticas culturais em narrativas escolares. 209 f. Tese (Doutorado em Educação) - Programa de Pós-Graduação em Educação, Faculdade de Educação, Universidade Federal do Rio Grande do Sul, Porto Alegre, 2006.

DELVAL, Juan. Introdução à prática do método clínico: descobrindo o pensamento das crianças. Porto Alegre: Artmed, 2002.

GERALDI, João Wanderley. Portos de passagem. 4. ed. São Paulo: Martins Fontes, 1997.

KOCH, Ingedore Grunfeld Villaça. A coesão textual. São Paulo: Contexto, 1989.

KOCH, Ingedore Grunfeld Villaça; TRAVAGLIA, Luis Carlos. A coerência textual. São Paulo: Contexto, 1990.

LINS E SILVA, Maria Emília; SPINILLO, Alina Galvão. A influência de diferentes situações de produção na escrita de histórias. Psicologia: Reflexão e Crítica, Porto Alegre, v. 13, n. 3, p. 337-350, 2000.

PIAGET, Jean; INHELDER, Bärbel. Da lógica da criança à lógica do adolescente. São Paulo: Pioneira, 1976.

PIAGET, Jean. A tomada de consciência. Tradução de Edson Braga de Souza. São Paulo: Melhoramentos, Editora da Universidade de São Paulo, 1977.

PIAGET, Jean. Fazer e compreender. Tradução de Christina Larroudé de Paula Leite. São Paulo: Melhoramentos, Editora da Universidade de São Paulo, 1978.

PIAGET, Jean. A noção de tempo na criança. Tradução de Rubens Fiúza. Rio de Janeiro: Record, [1980?].

PIAGET, Jean. O possível e o necessário: evolução dos possíveis na criança. Porto Alegre: Artes Médicas, 1985. v. 1.

PIAGET, Jean. O possível, o impossível e o necessário: as pesquisas em andamento ou projetadas no Centro Internacional de Epistemologia Genética. In: LEITE, Luci Banks (Org.). Piaget e a Escola de Genebra. São Paulo: Cortez, 1987. p. 51-71.

PIAGET, Jean. Psicologia e Epistemologia: para uma teoria do conhecimento. Tradução de Maria de Fátima Bastos e José Gabriel Bastos. Lisboa: Dom Quixote, 1991. 
PIAGET, Jean; GARCIA Rolando. Hacia una lógica de las significaciones. Barcelona: Editorial Gedisa, 1997.

PINHEIRO, Flávia Isaia. Epistemologia Genética e produção de textos na escola: estudo da construção da coerência em narrativas escritas escolares. Porto Alegre: UFRGS. 223 f. Tese (Doutorado em Educação) - Programa de Pós-Graduação em Educação, Faculdade de Educação, Universidade Federal do Rio Grande do Sul, Porto Alegre, 2012.

SPINILLO, Alina Galvão. A produção de histórias por crianças: a textualidade em foco. In: CORREA, Jane; SPINILLO, Alina; LEITÃO, Selma (Orgs.). Desenvolvimento da linguagem: escrita e textualidade. Rio de Janeiro: NAU Editora: FAPERJ, 2001. p. 73-116.

SPINILLO, Alina Galvão. O uso de coesivos por crianças com diferentes níveis de domínio de um esquema narrativo. In: DIAS, Maria da Graça B. B.; SPINILLO, Alina Galvão (Orgs.). Tópicos em Psicologia Cognitiva. Recife: Editora Universitária da UFPE, 1996. p. 84-119.

SPINILLO, Alina Galvão; MARTINS, Raul Aragão. Uma análise da produção de histórias coerentes por crianças. Psicologia: Reflexão e Crítica, Porto Alegre, Programa de Pós-Graduação em Psicologia da UFRGS, v. 10, n. 2, p. 219-248, 1997.

YIN, Robert K. Estudo de caso: planejamento e métodos. 3. ed. Porto Alegre: Bookman, 2010.

Texto recebido em 24 de fevereiro de 2014 . Texto aprovado em 24 de junho de 2014. 
